\title{
METÁFORA Y METONIMIA COMO MECANISMOS DE CREACIÓN DE LOCUCIONES VERBALES EUFEMÍSTICAS Y DISFEMÍSTICAS
}

\author{
Clara Ureña Tormo \\ Universidad de Alcalá
}

\section{RESUMEN}

Este estudio aborda los principales procesos metafóricos y metonímicos en la formación de locuciones eufemísticas y disfemísticas del ámbito de la 'muerte', en relación con los eventos de 'morir' y 'matar'. Concretamente, se comprueba que la esfera interdicta de la 'muerte' no solo se muestra proclive a la creación de eufemismos mediante los cuales se hace referencia al concepto proscrito de manera suavizada, sino también de disfemismos, con el efecto contrario: intensificando las connotaciones negativas de la muerte. Asimismo, se muestra que, además de la metáfora, la metonimia participa significativamente en la creación de locuciones eufemísticas/disfemísticas de esta realidad tabú. Por lo general, a partir de una concepción metafórica de base, la locución se construye tomando una parte del proceso de morir o de la acción de matar para referirse a todo el evento. Este proceso de formación se repite, por una parte, en locuciones eufemísticas como acordarse Dios, descansar en paz y enviar al otro mundo, las cuales se apoyan en una representación de la muerte basada en la religión; por otra parte, en locuciones disfemísticas como arrancar el pescuezo, ir al matadero y llevar al degolladero, las cuales, además, identifican al individuo con un animal mediante la metáfora LAS PERSONAS SON ANIMALES.

Palabras Clave: muerte, locución eufemística, locución disfemística, metáfora, metonimia.

\section{METAPHOR AND METONYMY AS MECHANISMS TO CREATE EUPHEMISTIC AND DYSPHEMISTIC VERBAL IDIOMS}

\section{Abstract}

This paper investigates the main metaphors and metonymies involved in the creation of euphemistic and dysphemistic idioms related to death, as regards to both 'dying' and 'killing'. This study shows that the taboo of death does not only produce euphemisms, with the aim of mitigating the reference to the prohibited concept, but dysphemisms, with the opposite effect: to intensify the negative aspects of death. In addition to metaphors, metonymies also participate actively in the creation of euphemistic/dysphemistic idioms. Based on a metaphorical representation of death, most idioms take one part of the process of dying or the action of killing to refer to the whole event. This process of idiom formation is repeated both in euphemistic idioms, mostly focusing on religious concepts (e.g. acordarse Dios, descansar en paz and enviar al otro mundo), and dysphemistic idioms, which often represent people as animals based on the metaphor PEOPLE ARE ANIMALS (e.g. arrancar el pescuezo, ir al matadero, and llevar al degolladero).

KeYwords: death, euphemistic idiom, dysphemistic idiom, metaphor, metonymy. 


\section{INTRODUCCIÓN}

En los estudios sobre interdicción lingüística, la muerte se presenta como el tabú más universal desde tiempos remotos hasta la actualidad (Crespo Fernández 2008: 83; Zhou 2018: 29). Siguiendo a Crespo Fernández (2005: 261-265), la principal causa que motiva el tabú de la muerte se relaciona con el miedo, base que también subyace al tabú de la enfermedad y lo sobrenatural. En tanto que realidad interdicta, por lo general, los hablantes tratan de evitar la referencia directa a la muerte, teniendo en cuenta toda una serie de factores que, además del miedo, comprenden el respeto hacia la persona difunta y su entorno, la actitud de cortesía ante un acto fúnebre, así como cuestiones religiosas y supersticiones (Crespo Fernández 2008: 84).

De lo anterior se deriva que la esfera de la muerte se muestra propensa al uso de palabras y expresiones que aluden a esta realidad de manera suavizada, con el objetivo de minimizar el efecto ofensivo o molesto que produciría su referencia lingüística directa. Este planteamiento se identifica, como no puede ser de otra manera, con el fenómeno del eufemismo. El estudio del tabú de la muerte ha sido ampliamente tratado por su relación con la creación de eufemismos (ej.: Crespo Fernández 2005, 2006, 2008; Georgijev 2019; Lope Blanc 1961; Zhou 2018); no obstante, la muerte también puede abordarse en relación con el fenómeno opuesto, el disfemismo, si bien los estudios en este sentido son más escasos, al menos en el campo del español (ej.: Mellado Blanco 2013). Asimismo, aunque la investigación lingüística sobre el tabú de la muerte se ha centrado, casi exclusivamente, en la producción de eufemismos/disfemismos que se refieren al proceso de morir, en este artículo se comprueba que estos también se muestran productivos en las referencias a la acción de matar, un tema que ha sido menos explorado desde esta perspectiva.

Por otra parte, en las investigaciones sobre la creación de eufemismos/disfemismos, en general, y sobre los propios del ámbito de la muerte, en particular, el recurso lingüístico de la metáfora ha recibido una atención destacada, en comparación con la metonimia (Alonso Moya 1978; Casas Gómez 2019). El presente trabajo demuestra que el mecanismo de la metonimia también ocupa un lugar significativo en la formación de locuciones eufemísticas y disfemísticas sobre los eventos de 'morir' y 'matar' que, en ningún caso, debe ser ignorado. Esto no implica, sin embargo, que la metáfora se vuelva irrelevante; al contrario, a menudo, las metonimias se apoyan sobre una concepción metafórica de la muerte basada en creencias y símbolos religiosos con un profundo arraigo en la cultura occidental, cuyo estudio constituye una parte fundamental de las investigaciones de Crespo Fernández (2005, 2006, 2008), Mellado Blanco (2013) y Zhou (2018), entre otros.

Este artículo aborda, así pues, la formación de eufemismos y disfemismos del ámbito de la muerte, en relación con los eventos de 'morir' y 'matar', a partir del estudio de los dos recursos de creación eufemística/disfemística de mayor relevancia: las metáforas y las metonimias conceptuales. Concretamente, el tipo de unidades lingüísticas que se abordan corresponden a locuciones verbales, definidas como combinaciones fijas de palabras que funcionan como elementos de la oración y tienen un significado idiomático que no se corresponde con la suma de los significados de sus constituyentes (Penadés Martínez 2012: 23). 
El corpus de estudio está constituido por un total de 131 locuciones registradas en el Diccionario de locuciones idiomáticas del español actual (DiLEA) (Penadés Martínez 2019a) que incluyen en su definición alguna referencia a la muerte y, en concreto, a los eventos de 'morir' o 'matar'. Para la elaboración de este trabajo, se ha procedido metodológicamente seleccionando algunas locuciones del total citado que ejemplifican los procesos eufemísticos/disfemísticos que se describen. El DiLEA no incluye las marcas eufemismo y disfemismo de las unidades que registra. Sin embargo, esto no supone un inconveniente para nuestro cometido, puesto que, partiendo de la concepción teórica de 'eufemismo' y 'disfemismo' propuesta por Casas Gómez (2009), planteamos una serie de consideraciones (apartado 2.) que facilitan el tratamiento de las unidades que se analizan, bien como locuciones eufemisticas (apartados 3. y 3.1.), bien como locuciones disfemísticas (apartados 4. y 4.1.). De esta manera, además, se intentan salvar las dificultades que pueden surgir a la hora de identificar los eufemismos y los disfemismos, dificultades que no siempre se resuelven con la consulta lexicográfica dada la escasa $-y$, a veces, inconsistente- información sobre la marcación de los sustitutos eufemísticos y disfemísticos en los diccionarios, al menos, en lo que concierne a las locuciones (Penadés Martínez 2019b).

Por otra parte, para describir los procesos implicados en la formación de las locuciones eufemísticas/disfemísticas, las principales decisiones metodológicas tomadas se apoyan en la teoría de la metáfora conceptual de Lakoff y Johnson (1980), en el marco de la lingüística cognitiva. Partiendo de esta base, para explicar las unidades objeto de estudio, se toman como referencia las principales metáforas y metonimias planteadas en investigaciones previas sobre el eufemismo/disfemismo de la 'muerte' (Crespo Fernández 2005, 2006, 2008; Mellado Blanco 2013; Zhou 2018) y se adaptan o se formulan otras nuevas. Además, siguiendo la teoría del lenguaje figurado convencional de Dobrovol'skij y Piirainen (2005), se presta especial atención al conocimiento cultural asociado a los fraseologismos, en concreto a creencias y simbología religiosas ${ }^{1}$ que motivan la representación metafórica/metonímica de la muerte en algunas locuciones.

${ }^{1}$ Como ejemplo, las locuciones descansar en el Señor y entregar el alma a Dios manifiestan claramente las creencias religiosas cristianas, mientras que ir al degolladero y llevar al degolladero parten de la simbología cristiana que representa a Jesucristo como un cordero que muere para salvar a la humanidad, sacrificado de manera análoga a como los judíos sacrificaban animales. 


\section{LOS CONCEPTOS DE 'EUFEMISMO' Y 'DISFEMISMO' EN LA CARACTERIZACIÓN DE LAS LOCUCIONES EUFEMÍSTICAS Y DISFEMÍSTICAS}

A medida que los estudios sobre el eufemismo avanzan, se van sucediendo definiciones distintas, más o menos relacionadas, sobre este fenómeno ${ }^{2}$. A pesar de las aproximaciones variadas al concepto de 'eufemismo', la mayoría de los autores coinciden en señalar su función encubridora y atenuadora (Casas Gómez 2012a: 52), en el marco de un acto de cortesía que contribuye a preservar la imagen positiva del hablante y del oyente. Así, por una parte, el sustituto eufemístico puede encubrir el concepto prohibido mediante ciertos elementos lingüísticos que eviten las denotaciones o las connotaciones negativas propias de los términos interdictos directos (Cestero Mancera 2015: 25). Por otra parte, el eufemismo puede realizar la función de atenuar, sirviéndose de elementos lingüísticos que, en este caso, reduzcan o eliminen la tensión social que supondría una referencia directa al concepto interdicto, con el objeto de evitar amenazas a las relaciones sociales o a las imágenes ( face) del emisor y del receptor (Cestero Mancera 2015: 25).

Además de encubrir y atenuar, el eufemismo cumple la función de realzar la realidad prohibida con la intención de enfatizar algún aspecto que la revalorice y permita obtener una visión positiva de ella (Casas Gómez 2012a: 61, Casas Gómez 2012b: 76-77 ; Edeso Natalías 2009: 158-159). Esta función parece relacionarse más con situaciones en las que se busca dar prestigio a determinadas profesiones u oficios por razones de decoro (Casas Gómez 2012a: 54), de manera que su incidencia en el estudio del tabú de la muerte es menor.

Como fenómeno opuesto al eufemismo, el disfemismo se caracteriza por acentuar el «concepto proscrito» y romper con el «convencionalismo social» (Casas Gómez 1986: 85), centrando la atención en los aspectos más negativos y ofensivos de la realidad prohibida o tabú. Más concretamente, Crespo Fernández (2005: 136) define el disfemismo como

el proceso que, en un determinado contexto discursivo, refuerza los matices más ofensivos o inaceptables que se establecen entre el tabú y su manifestación lingüística por medio de un acto de habla que, como sustituto eufemístico, actualiza la intención del emisor de ofender o incomodar al receptor.

Desde una dimensión cognitivo-pragmática, Casas Gómez (2009: 736-737; 2012b: 56) describe los dos fenómenos, eufemismo y disfemismo, como posibles procesos mediante los que se conceptualiza una realidad interdicta, cada uno de los cuales tiene objetivos específicos y produce un efecto discursivo diferente. Concretamente, el hablante se sirve de una gran variedad de recursos lingüísticos que le permiten encubrir dicha realidad, atenuarla y realzarla expresivamente, en el caso

tacadas.

2 Casas Gómez (2009) recoge de manera sistemática algunas de las definiciones más des- 
del eufemismo, o motivarla y reforzarla evocativamente, en el del disfemismo. Este planteamiento se corresponde con una concepción del eufemismo y el disfemismo que los define como fenómenos discursivos que se actualizan en el contexto y están sujetos a elementos pragmáticos derivados de la situación comunicativa concreta (Casas Gómez 2009: 736³; Crespo Fernández 2005: 136).

Consideramos que este enfoque de naturaleza pragmático-discursiva ofrece la posibilidad de investigar el funcionamiento y el uso real de los eufemismos en el discurso -y, añadimos, los disfemismos-. No obstante, cabe preguntarse si este planteamiento, sumado a las definiciones afines que se ofrecen de los dos fenómenos (Casas Gómez 2012a: 43), realmente facilita la tarea del investigador a la hora de distinguir el eufemismo del disfemismo -y viceversa-, o todo lo contario. En lo que se refiere al análisis de las locuciones eufemísticas y disfemísticas en concreto, observamos que el enfoque pragmático-discursivo propuesto debe complementarse con otra perspectiva de estudio que preste atención a los aspectos léxico-semánticos, así como a la naturaleza metafórica y metonímica propia de esta clase de fraseologismos.

La identificación de locuciones eufemísticas y disfemísticas de una determinada realidad interdicta podría desarrollarse atendiendo a múltiples aspectos. De todos ellos, en este trabajo proponemos abordar los que se enmarcan en cuatro dimensiones concretas: léxico-semántica, pragmática, conceptual y discursiva. En primer lugar, desde una dimensión léxico-semántica, es esencial prestar atención a la imagen mental que provoca la lectura literal de la combinación de palabras. Cuando la imagen resultante es violenta, brusca o amenazante, esto debe entenderse como un indicador de que la locución se aproxima hacia los valores disfemísticos. Por ejemplo, la lectura literal de los elementos que forman la locución arrancar la piel a tiras evoca una imagen agresiva en la mente del hablante/oyente que, en ningún caso, suaviza o atenúa la referencia directa a la muerte, sino todo lo contrario.

En segundo lugar, y en relación, asimismo, con la dimensión léxico-semántica, desde la dimensión pragmática, el uso de una locución como la anterior, con la consecuente imagen mental que evoca, puede dañar la imagen, tanto del emisor como del receptor. Esto es, teniendo en cuenta los fenómenos de la cortesía y la imagen pública, los eufemismos permiten al hablante preservar su imagen pública y su prestigio social (cortesía positiva), al tiempo que compensan la posible amenaza a la imagen del interlocutor con el objetivo de favorecer las buenas relaciones sociales (cortesía negativa) (Crespo Fernández 2005: 83). Los disfemismos, por el contrario, no actúan dentro del marco de la cortesía.

En tercer lugar, desde una dimensión conceptual, las metáforas y las metonimias constituyen mecanismos cognitivos implicados en la formación de buena parte de las locuciones y motivan sus significados idiomáticos (Lakoff 1987: 446-453),

3 Como resultado de concebir el eufemismo y el disfemismo como fenómenos sociales y discursivos, Casas Gómez (2009: 731) descarta la existencia de palabras o expresiones eufemísticas y disfemísticas en sí mismas, en favor de la única existencia de usos eufemisticos y usos disfemísticos de la lengua, dependientes del contexto y la situación comunicativa. El presente trabajo no trata en profundidad esta propuesta, puesto que queda fuera de su principal cometido. 
de manera completamente independiente a si estas presentan un carácter eufemístico/disfemístico o no. Además de esto, las metáforas y las metonimias se presentan como recursos relevantes que participan en los procesos de formación de sustitutos eufemísticos/disfemísticos. En este sentido, siguiendo a Casas Gómez (2019: 258), normalmente, cuanto mayor es la distancia entre la esfera interdicta-que actúa como concepto metaforizado- y el uso metafórico, mayor se considera la «eficacia eufemística». Por ejemplo, la locución irse a criar malvas se refiere a la muerte a partir de la realidad del cultivo de plantas (Zhou 2018: 253), con la cual mantiene una distancia conceptual pronunciada, lo que se traduce en una eficacia eufemística clara. Por el contrario, la locución correr ríos de sangre carece de eficacia eufemística, en tanto que se apoya en una metonimia que vincula directamente la consecuencia de matar con la acción de matar en sí misma. Esto se debe a la relación de contigüidad que mantienen estos dos elementos, enmarcados dentro del mismo dominio de conocimiento.

En cuarto lugar, la dimensión discursiva se relaciona con las funciones de atenuación, encubrimiento o realce expresivo de los eufemismos, y de motivación o refuerzo expresivo de los disfemismos en el discurso (Casas Gómez 2009). Esta dimensión puede ser especialmente útil para examinar, mediante ejemplos de uso concretos, las locuciones eufemísticas/disfemísticas que no se identifican fácilmente a partir de las dimensiones anteriormente descritas. Por ejemplo, Mellado Blanco (2013: 111) clasifica la locución estirar la pata como un disfemismo humorístico, mientras que Zhou (2018: 177-178) la incluye en su corpus de eufemismos lingüísticos, señalando que, según el contexto en el que aparece, esta locución puede realizar una función intensificadora y disfemística, pero también mitigadora y eufemística. Otra locución cuya condición de eufemismo o disfemismo suscita ciertas dudas es liar el petate, tal como se observa en los dos ejemplos siguientes:

(1) Quedó, en cambio, un retén de mozos de El Ángel de Tobias, con el furgón de los cachivaches de urgencia, por llamarlos de alguna manera (floreros, candelas, sudarios y cosméticos), por si «se volvia la tortilla» (esto con el mayor respeto) y el moribundo decidía "liar el petate».

(2) Aunque tiene usted vida para muchos años, y Dios se la aumente, hágase cuenta de que llega la hora de liar el petate...

En el ejemplo (1) el uso de la locución adquiere un valor disfemístico que se ve acrecentado por el tono sarcástico del texto (furgón de los cachivaches, se volvía la tortilla -aunque, en este caso, la burla quede atenuada por esto con el mayor respeto-) y el uso del término moribundo como una forma despectiva de referirse a la persona que va a morir (a liar el petate). Por el contrario, en el ejemplo (2), la locución ilustra un uso eufemístico con el que se mitiga la referencia a la muerte que intenta evitarse.

Estos dos ejemplos muestran las dificultades que pueden surgir a la hora de asignar un único carácter eufemístico o disfemístico a una locución, independientemente del contexto. Somos conscientes de que el uso de una locución en el discurso puede asignarle valores distintos (eufemísticos o disfemísticos) a los que podría 
tener si únicamente se examina su forma canónica. Atender esta dimensión discursiva en profundidad requeriría llevar a cabo un detallado análisis de un amplio corpus de ejemplos de uso, lo cual excedería nuestro objetivo: describir las metáforas y las metonimias subyacentes a las locuciones del DiLEA relacionadas con la 'muerte'. Así, en los siguientes apartados, abordamos las locuciones como eufemísticas o disfemísticas a partir de su forma canónica, aportando algunos ejemplos ${ }^{4}$ que ilustran el carácter eufemístico/disfemístico que se les asigna, al margen de los valores que puedan adquirir en contextos particulares 5 . De esta manera, nos acercamos a la postura de Penadés Martínez (2019b: 705), según la cual cabría considerar la existencia de términos que son «intrínsecamente eufemísticos o potencialmente eufemísticos, independientemente del uso particular (eufemístico o no) que el hablante pueda hacer de ellos en un discurso concreto, frente a los que no lo son per se».

\section{LA METÁFORA Y LA METONIMIA EN LA CREACIÓN DE LOCUCIONES EUFEMÍSTICAS SOBRE LA MUERTE}

La formación de eufemismos y disfemismos se apoya en una serie de mecanismos variados pertenecientes a todos los niveles lingüísticos (fonético, morfológico, léxico, semántico, textual, etc.), entre los cuales sobresale la metáfora como el recurso interdictivo con "mayores dimensiones funcionales y cognitivas» (Casas Gómez 2019: 256). De acuerdo con la teoría de la metáfora conceptual (Lakoff y Johnson 1980), las metáforas conceptuales se presentan como mecanismos cognitivos mediante los cuales se expresan conceptos pertenecientes a dominios abstractos -que, en este caso, se identifican con la realidad interdicta o tabú (la muerte)-, a través de conceptos propios de otros dominios más concretos, por la relación de similitud que existe entre ambos conceptos. Por ejemplo, la metáfora LA MUERTE ES EL DESCANSO permite abordar una noción tan compleja como 'morir' a partir de una acción común y cotidiana como descansar, mediante una serie de proyecciones metafóricas que relacionan los dos dominios. Esta metáfora actúa, así pues, como el principal recurso involucrado en el proceso eufemístico a partir del cual se genera la locución dejar de sufrir y la serie de locuciones descansarldormirse en el Señor ${ }^{6}$, descansarldormirse en la paz del Señor y descansar en paz.

${ }^{4}$ Los ejemplos de este artículo se han extraído del CREA, el DiLEA y distintas páginas de internet, y se aportan especialmente de las locuciones cuyo carácter eufemístico/disfemístico puede suscitar dudas.

${ }^{5}$ Esta decisión se apoya en la investigación lexicográfica desarrollada sobre los eufemismos y su marcación en los diccionarios, la cual carecería de sentido si se considera que no hay eufemismos lexicalizados (Penadés Martínez 2019b). Así, es un hecho que los diccionarios, aunque escasamente, marcan unidades como eufemísticas; no como disfemísticas, si bien el disfemismo se puede vincular a la marca vulgar de los diccionarios y a otras semejantes. El tratamiento de la marcación diafásica de las locuciones eufemísticas se aborda en profundidad en Penadés Martínez (en prensa).

${ }^{6}$ Siempre que es posible, las variantes léxicas de una locución se presentan unidas, con los elementos distintos separados mediante barras. 
Por lo general, el mecanismo de la metáfora se relaciona con la función atenuadora propia de los eufemismos (Casas Gómez 2019: 257), en el sentido de que los eufemismos generados a partir de metáforas se perciben como «más suaves y menos rudos» que una referencia directa a la realidad prohibida (Zhou 2018: 58). Esta capacidad eufemística de la metáfora se apoya, siguiendo a Casas Gómez (2019: 257), en dos planteamientos fundamentalmente. Primero, en el "poder intrínseco y mágico de la palabra", por el que se produce una identificación total entre la palabra y la realidad que designa y, en consecuencia, constituye la base de la interdicción lingüística (Casas Gómez 1996: 30-31). Segundo, en una aproximación a la metáfora en la que, basándose en la relación de similitud entre una entidad de la esfera interdicta y otra entidad ajena a ella, la metáfora suprime algunos rasgos que pretenden eludirse y destaca otros comunes a las dos entidades. Así, la metáfora anterior, LA MUERTE ES EL DESCANSO 7 , vincula la muerte con el descanso, concretamente con el «reposo eterno» (Crespo Fernández 2008: 90), y, de esta manera, oculta las connotaciones negativas de la muerte al tiempo que pone de relieve las positivas. Para ello, se basa en la creencia cristiana, según la cual, al morir, el difunto alcanza el merecido descanso eterno, después de las penurias de la vida terrenal (Crespo Fernández 2008: 91).

Relacionados con los procesos metafóricos, Casas Gómez (2019: 256) distingue otros mecanismos de creación eufemística/disfemística como la metonimia, la hipérbole, la perífrasis, etc. De entre ellos, nos interesa reparar en la metonimia, definida, a partir de la teoría de Lakoff y Johnson (1980), como el mecanismo mediante el cual una entidad de un dominio cognitivo actúa como punto de referencia para designar otra entidad distinta -la realidad interdicta-, dentro del mismo dominio, con la que mantiene una relación de contigüidad. El estudio de la metonimia vinculado a la conceptualización de realidades prohibidas o tabúes está bastante menos extendido que el relativo a la metáfora, pero, en cualquier caso, su tratamiento también se relaciona fundamentalmente con el eufemismo. En este sentido, la función de la metonimia consiste en «atenuar el vocablo vitando por el proceso de sustitución, puesto que el sustituto eufemístico sugiere su contenido indicando un hecho contiguo» (Zhou 2018: 60).

En la formación de locuciones del ámbito de la muerte en particular, la metonimia adquiere un papel especialmente relevante en los casos en que se utiliza una parte del proceso de morir o un aspecto concreto de la acción de matar para referirse a todo el proceso o a toda la acción. De esta manera, la referencia a los eventos de 'morir' y 'matar' no se realiza de manera directa, sino a partir de un elemento que mantiene una relación contigua con estas realidades. Por ejemplo, la locución anterior dejar de sufrir, además de basarse en la metáfora LA MUERTE ES EL DESCANSO, conceptualiza el proceso de morir a partir de una de sus consecuen-

Esta metáfora tiene su origen en el cristianismo bíblico y la vinculación del dominio de la muerte con el del sueńo, más concretamente, morir se identifica con «dormir el sueño de los justos» $\mathrm{y}$ «dormir el sueño eterno» (Chamizo Domínguez 2004: 47). 
cias: la de cesar el sufrimiento del ya difunto, lo que está motivado por la participación de la metonimia UNA CONSECUENCIA DE MORIR POR EL PROCESO DE MORIR. Esta metonimia también subyace a las otras locuciones citadas (ej.: descansar en el Señor, descansar en la paz del Señor), pero, en su caso, la muerte y el descanso se relacionan específicamente con la consecuencia de estar con Dios, a partir de la metonimia más concreta ESTAR CON DIOS POR MORIR. Tanto esta metonimia como la anterior (UNA CONSECUENCIA DE MORIR POR EL PROCESO DE MORIR) se incluyen dentro de la metonimia más general UNA PARTE DEL PROCESO DE MORIR POR TODO EL PROCESO, la cual constituye una manifestación particular de la sinécdoqUe LA PARTE POR EL TODO.

\subsection{Procesos metafóricos y metonímicos Subyacentes a las locuciones EUFEMÍSTICAS ANALIZADAS}

De lo expuesto al final del apartado anterior se desprende que las metáforas y las metonimias a menudo se combinan en la formación de locuciones eufemísticas del ámbito de la muerte. Más concretamente, existen metáforas conceptuales generales que reflejan distintas representaciones metafóricas de la muerte, sobre las cuales se apoyan, además, las metonimias. Tal como hemos señalado, estas metonimias utilizan un aspecto de la muerte, esto es, una parte del proceso de morir o un aspecto de la acción de matar, para designar el proceso de morir o la acción de matar en su totalidad, así: UNA PARTE DEL PROCESO DE MORIR POR TODO EL PROCESO Y UN ASPECTO DE LA ACCIÓN DE MATAR POR TODA LA ACCIÓN.

Por otro lado, a continuación, desarrollamos la posibilidad de que algunos procesos que han sido considerados metafóricos en investigaciones anteriores (Crespo Fernández 2008; Zhou 2018), en realidad, comprendan un único dominio cognitivo (el de la muerte) y, en consecuencia, se relacionen con el mecanismo de la metonimia, y no con el de la metáfora. Partiendo de esta idea, en nuestro análisis las metáforas MORIR ES SUBIR AL CIELO y MORIR eS ESTAR CON Dios (Crespo Fernández 2008: 92; Zhou 2018: 204, 226), entre otras, se reformulan de acuerdo con su condición de metonimias del siguiente modo: SUBIR AL CIELO POR MORIR y ESTAR CON DiOS POR MORIR. En lo que sigue de este apartado se describen, pues, algunos procesos metafóricos y metonímicos de creación de locuciones eufemísticas relacionadas con los eventos de 'morir' y 'matar'. Al mismo tiempo, se incluyen referencias concretas al componente religioso de buena parte de las locuciones de este campo, puesto que influye profundamente en su representación metafórica/metonímica de la muerte.

En primer lugar, la muerte puede conceptualizarse como un viaje que realiza el difunto (o, más concretamente, su alma), desde el mundo terrenal hacia el cielo o el infierno, a partir de la metáfora LA MUERTE ES UN VIAJE (Lakoff y Turner 1989: 7-11). Sobre esta metáfora general se apoyan metonimias más concretas como: a) MARCHARSE AL MUNDO CELESTIAL POR MORIR, que da lugar a las locuciones irse al otro mundo e irse de este mundo; b) SUBIR AL CIELO POR MORIR, subyacente a la locución volar al cielo; y c) PROVOCAR QUE UNA PERSONA SE MARCHE 
AL MUNDO CELESTIAL POR MATAR, en enviar/mandar al otro mundo y llevar al otro mundo. Estas metonimias se basan en la creencia cristiana de que la muerte implica la partida del difunto hacia el mundo celestial, concretamente, la ascensión del alma al cielo. Así, toman una consecuencia de la muerte (dejar este mundo) para referirse a la muerte en sí misma. Las dos primeras metonimias se incluyen dentro de la metonimia más general UNA PARTE DEL PROCESO DE MORIR POR TODO EL PROCESO, mientras que la tercera se corresponde con UN ASPECTO DE LA ACCIÓN DE MATAR POR TODA LA ACCIÓN.

Las locuciones propuestas, irse al otro mundo, irse de este mundo, volar al cielo, enviar/mandar al otro mundo y llevar al otro mundo, suavizan la expresión lingüística de las realidades tabú 'morir' y 'matar' mediante el uso de verbos como irse, enviar, mandar, llevar y volar. Además, el carácter eufemístico de las locuciones que contienen el lexema otro mundo se apoya en el significado de la locución nominal el otro mundo, definida en el DFDEA como 'El lugar donde, según distintas creencias, viven las almas después de la muerte corporal'. Así, un suceso desagradable, el de morir o matar, se presenta de manera positiva porque se va a un lugar donde se sigue viviendo aun habiendo muerto. Si bien estas locuciones podrían adquirir valores diferentes en contextos particulares, los ejemplos siguientes muestran el carácter eufemístico de dos de ellas:

(3) Tenia 50 años, una edad demasiado temprana para irse de este mundo.

(4) -Vamos, que sin pedirnos permiso nos mandaron al otro mundo -le respondi yo-. Pues mire usted, no me acuerdo de nada de esto.

En el ejemplo (3) el sentimiento de pesar que se desprende por la muerte temprana del individuo justifica el uso del eufemismo. Por su parte, en el ejemplo (4) el hablante mitiga la referencia a su propia muerte ante un interlocutor con quien mantiene una relación de distanciamiento o formalidad, como señala el uso del pronombre usted.

En segundo lugar, también siguiendo la visión cristiana, la muerte puede representarse metafóricamente como la separación del alma respecto del cuerpo del difunto, a partir de la metáfora LA MUERTE ES LA SEPARACIÓN DEL ALMA RESPECTO DEL CUERPO. Esta representación conceptual sirve de base a la metonimia ENTREGAR El ALMA A Dios por MORIR, en la que la acción de dar el alma actúa como el punto de referencia que activa el efecto que esta acción produce en el individuo: la muerte, pues quedarse desprovisto del alma no implica sino la muerte de una persona. Esta metonimia, reflejo de una relación de causa-consecuencia, da lugar a la siguiente serie de locuciones: darlentregar/rendir el alma a Dios, darlrendir su alma, entregarlrendir el alma, entregar el espiritu y rendir su alma al Altísimolal Señor.

\footnotetext{
${ }^{8}$ El verbo rendir se entiende a partir de su tercera acepción en el $D L E$ : 'dar a alguien lo que le toca, o restituirle aquello de que se le había desposeído’.
} 
En tercer lugar, el proceso de morir puede conceptualizarse eufemísticamente destacando el encuentro del difunto con Dios, a partir de la metáfora LA muerte es ReEncontrarse con Dios. Por una parte, esta concepción metafórica de la muerte constituye la base de las metonimias ACORDARSE DIOS POR MORIR y LLAMAR DiOS POR MORIR, en las que una acción previa a la muerte (que Dios se acuerde del individuo o lo llame) activa la referencia a la muerte en sí misma. Estas metonimias se incluyen dentro de la metonimia más general UNA PARTE DEL PROCESO DE MORIR POR TODO EL PROCESO y producen la siguiente serie de locuciones: acordarse Dios, llamar Dios, llamar Dios a su presenciala su seno, llamar el Señor y llamar el Señor a su presenciala su seno, basadas en la creencia cristiana de que «Dios, que nos infundió la vida, nos la retira en el momento que Él considera oportuno» (Montero Cartelle 1981: 120).

Por otra parte, la representación metafórica de la muerte como el reencuentro del difunto con Dios da lugar, asimismo, a la metonimia ESTAR CON Dios POR MORIR, que subyace a la locución pasar a la presencia del Señor y a la variante pasar a presencia del Señor. En este caso, el proceso de morir se conceptualiza eufemísticamente destacando el resultado positivo de la muerte: el posterior encuentro con Dios, y se distingue, así, del proceso anterior, el cual conceptualiza la muerte centrándose, precisamente, en una acción que se entiende previa a la muerte. Las locuciones descansarldormirse en el Señor, descansarldormirse en la paz del Señor y descansar en paz, las cuales se han tratado más arriba, también se forman a partir de la metonimia ESTAR CON DIOS POR MORIR, pero, en este caso, la concepción metafórica de base corresponde a la metáfora LA MUERTE ES EL DESCANSO.

El planteamiento expuesto, en el que la metonimia se muestra ciertamente relevante en la creación de locuciones eufemísticas, tendría algunas implicaciones sobre los estudios previos que han tratado los eufemismos de la muerte desde el recurso de la metáfora. Por ejemplo, apoyándose en otros autores, Crespo Fernández (2008: 85) asegura que «la metáfora constituye un importante recurso eufemístico" y "un modo habitual de abordar la muerte». Sin dejar de ser cierta esta afirmación en ninguno de los casos, convendría plantearnos si la metonimia debería ocupar un lugar más destacado en el estudio del tabú de la muerte que el que ha tenido hasta el momento. Zhou (2018) ya deja ver la importancia de este recurso en la conceptualización de la muerte al formular la metonimia CONFIAR EL ALMA A DIOS POR MORIR y al señalar que las metáforas LA MUERTE ES UN VIAJE DEL ALMA Y LA MUERTE ES UN ESTADO DEL ALMA se basan en la metonimia UNA PARTE DE LA ESCENA POR TODA LA ESCENA. Sin embargo, la autora no llega a plantear la posibilidad de que haya casos que, en realidad, no ponen en relación dos dominios diferentes, sino que un elemento activa la referencia a otro elemento del mismo dominio, y, en consecuencia, su condición de metáforas debería replantearse.

La tabla 1 recoge las metáforas y las metonimias que se han descrito en este apartado acompañadas de las locuciones que las ejemplifican. 


\begin{tabular}{|c|c|c|}
\hline \multicolumn{3}{|c|}{$\begin{array}{l}\text { TABLA 1. METÁFORAS Y METONIMIAS CONCEPTUALES DEL ÁMBITO } \\
\text { DE LA MUERTE EJEMPLIFICADAS CON LOCUCIONES EUFEMÍSTICAS }\end{array}$} \\
\hline $\begin{array}{l}\text { Metáforas } \\
\text { CONCEPTUALES }\end{array}$ & METONIMIAS CONCEPTUALES & LOCUCIONES EUFEMÍSTICAS \\
\hline \multirow{2}{*}{ La muerte es el descanso } & $\begin{array}{l}\text { Una consecuencia de morir por el } \\
\text { proceso de morir }\end{array}$ & dejar de sufrir \\
\hline & Estar con Dios por morir & $\begin{array}{l}\text { descansarldormirse en el Señor, descansarl } \\
\text { dormirse en la paz del Señor, descansar en paz }\end{array}$ \\
\hline \multirow{3}{*}{ La muerte es un viaje } & $\begin{array}{l}\text { Marcharse al mundo celestial por } \\
\text { morir }\end{array}$ & irse al otro mundo, irse de este mundo \\
\hline & Subir al cielo por morir & volar al cielo \\
\hline & $\begin{array}{l}\text { Provocar que una persona se mar- } \\
\text { che al mundo celestial por matar }\end{array}$ & $\begin{array}{l}\text { enviarlmandar al otro mundo, llevar al otro } \\
\text { mundo }\end{array}$ \\
\hline $\begin{array}{l}\text { La muerte es la separación } \\
\text { del alma respecto del cuerpo }\end{array}$ & Entregar el alma a Dios por morir & $\begin{array}{l}\text { darlentregar/rendir el alma a Dios, darl } \\
\text { rendir su alma, entregar/rendir el alma, } \\
\text { entregar el espiritu y rendir su alma al Al- } \\
\text { tísimolal Señor }\end{array}$ \\
\hline \multirow{3}{*}{$\begin{array}{l}\text { La muerte es reencontrarse } \\
\text { con Dios }\end{array}$} & Acordarse Dios por morir & acordarse Dios \\
\hline & Llamar Dios por morir & $\begin{array}{l}\text { llamar Dios, llamar Dios a su presenciala su } \\
\text { seno, llamar el Señor y llamar el Señor a su } \\
\text { presenciala su seno }\end{array}$ \\
\hline & Estar con Dios por morir & pasar a (la) presencia del Señor \\
\hline
\end{tabular}

\section{LA METÁFORA Y LA METONIMIA EN LA CREACIÓN DE LOCUCIONES DISFEMÍSTICAS SOBRE LA MUERTE}

Las investigaciones lingüísticas sobre el tabú de la muerte lo abordan mayoritariamente en relación con la creación de eufemismos (Crespo Fernández 2006, 2008; Georgijev 2019; Lope Blanc 1961; Zhou 2018). Así, se considera que este ámbito se muestra proclive a la «recategorización eufemística» (Barley 2000: 56) de tal forma que, en las producciones escritas que hacen referencia a la muerte, el eufemismo «resulta imprescindible» (Crespo Fernández 2008: 84). Delimitando nuestro objeto de estudio a la clase de las locuciones verbales, Penadés Martínez (2019b: 712) señala:

[...] aunque no exista un acuerdo total en relación con las esferas que originan la interdicción lingüística ni con su organización, sí podría aceptarse que al menos la religión, la muerte, la enfermedad, el sexo, las funciones corporales y diversos aspectos sociales son ámbitos proclives a generar, a lo largo del tiempo y del espacio de desarrollo de una lengua, unidades lingüísticas eufemísticas. Por tanto, las locuciones verbales cuyos significados correspondan a alguno de esos conceptos están destinadas, en principio, a ser marcadas como eufemísticas en un diccionario. 
No obstante, el ámbito de la muerte, además de producir eufemismos, también atańe a la creación del fenómeno contrario, los disfemismos. Siguiendo a Mellado Blanco (2013: 108), motivados por el «miedo atávico» que la muerte ocasiona en el ser humano, los eufemismos, pero también los disfemismos, se muestran frecuentes en este campo conceptual, con el objetivo de evitar el uso de los ortofemismos morir $-\mathrm{y}$ ańadimos, matar $-\mathrm{y}$ muerte. De hecho, la citada autora sostiene que, con el paso del tiempo, el uso de eufemismos del ámbito de la muerte se ha reducido mientras que el de disfemismos ha aumentado (Mellado Blanco 2013: 112). Considera, además, que los disfemismos que aluden a la realidad tabú de la muerte suelen hacerlo utilizando un tono humorístico, con lo que se establece, de inmediato, una cierta distancia con respecto al evento y se relativiza su importancia (Mellado Blanco 2013: 110). En relación con estas apreciaciones, cabe puntualizar que los disfemismos de la esfera de la muerte no siempre adoptan un carácter jocoso. Por el contrario, también pueden utilizarse con la intención de resaltar, precisamente, la parte más cruel, atroz y violenta de la muerte. Por ejemplo, las siguientes locuciones disfemísticas, arrancar la piel a tiras y perder el pellejo, destacan los aspectos más ofensivos de la muerte, tal como se desprende de la lectura literal de sus elementos, los cuales describen una realidad en la que el individuo se queda desprovisto de su propia piel. Los enunciados siguientes, en los que se hace referencia al grupo terrorista ETA y a la violencia de las muertes que provoca, ilustran el valor asignado a estas dos locuciones:

(5) Un etarra amenaza a un juez con arrancarle la piel a tiras y pegarle 7 tiros.

(6) El santo temor, personal y de su colectivo local, de perder el pellejo si la ETA, ahora agazapada y con las uñas afiladas, vuelve a las andadas.

Por otra parte, Casas Gómez (2019: 257) explica que, aunque la metáfora y la metonimia se conciben generalmente como mecanismos de formación de eufemismos con una función atenuadora, algunos estudios muestran que la metáfora no siempre tiene una "capacidad ocultadora", es decir, no se ocupa de romper las asociaciones entre «el sustituyente y el sustituido", sino de reforzar los aspectos en común. Destacamos, en este sentido, el trabajo de Montero Cartelle (1973, citado en Casas Gómez 2019: 257), en el que la metáfora se define como el mecanismo fundamental del disfemismo, precisamente, porque permite poner de relieve ciertos aspectos del elemento comparado -que pueden ser los más negativos, peyorativos y despectivos- y, al mismo tiempo, ocultar los demás. Junto con la metáfora, la metonimia también puede participar en la formación de locuciones disfemísticas. $\mathrm{Y}$, tal como se comprueba en el apartado siguiente, es común que ambos mecanismos actúen de manera combinada, de la misma forma que en la creación de eufemismos. 


\subsection{Procesos metafóricos y metonímicos Subyacentes a las locuciones DISFEMÍSTICAS ANALIZADAS}

En las distintas aproximaciones disfemísticas a la esfera de la muerte, primeramente, esta realidad puede representarse enfatizando la relación que existe entre 'morir' o 'matar' y la falta de integridad corporal del individuo, a partir de la metáfora LA MUERTE ES LA FALTA DE INTEGRIDAD CORPORAL. En un nivel más específico, esta metáfora constituye la base de la metonimia PERDER LA INTEGRIDAD POR MORIR, que se materializa en la locución perder el pellejo, y de la metonimia DEsTRUIR LA INTEGRIDAD POR MATAR, la cual da lugar a un amplio conjunto de locuciones disfemísticas como arrancarlpartir/romper el alma, arrancarlsacar la piel a tiras, comer/sacar los higados, hacer carnelmortadelalpicadillo, retorcer el pescuezo y reventar como un triquitraque. En estos fraseologismos, los aspectos más violentos del proceso de morir y de la acción de matar se ponen de relieve para referirse a cada uno de los dos eventos en su totalidad. Se observan, por consiguiente, las mismas metonimias que se han señalado en relación con las locuciones eufemístiCAS: UNA PARTE DEL PROCESO DE MORIR POR TODO EL PROCESO Y UN ASPECTO DE LA ACCIÓN DE MATAR POR TODA LA ACCIÓN, las cuales se articulan de una manera concreta en cada caso en particular. Además, en las locuciones arrancarlsacar la piel a tiras, comer/sacar los higados, hacer carnelmortadelalpicadillo y retorcer el pescuezo se observa la metáfora LAS PERSONAS SON ANIMALES, pues las acciones a las que se refiere la imagen mental de las locuciones se llevan a cabo, en principio, sobre animales. Por ejemplo, se comen y sacan los hígados de animales; se hace carne, mortadela y picadillo de carne de animales; y se retuerce el pescuezo a los pollos y a las gallinas para matarlos.

Las metonimias UNA PARTE DEL PROCESO DE MORIR POR TODO EL PROCESO Y UN ASPECTO DE LA ACCIÓN DE MATAR POR TODA LA ACCIÓN se muestran, igualmente, productivas en las locuciones que se presentan a continuación, concretizándose, de nuevo, en metonimias particulares. Así, en segundo lugar, una posibilidad alternativa es identificar la muerte con el lugar donde se muere o se mata a partir de la metáfora LA MUERTE ES ESTAR EN EL LUGAR DE LA MUERTE, que motiva las metonimias IR AL LUGAR DONDE SE MUERE POR MORIR, en las variantes léxicas ir al degolladero e ir al matadero y LLEVAR A UNA PERSONA AL LUGAR DONDE SE MATA POR MATAR en llevar al degolladero y llevar/mandar al matadero. En estas dos series de locuciones también está presente la metáfora LAS PERSONAS SON ANIMALES (pues es en un degolladero o en un matadero donde se produce la muerte de reses o de ganado), metáfora mediante la cual la persona que muere se identifica con un animal, lo que realza la crueldad de la expresión y acrecienta su valor disfemístico.

En tercer lugar, por lo que se refiere al evento de 'matar' exclusivamente, la muerte puede representarse metafóricamente como el hecho de dejar de existir (LA MUERTE ES INEXISTENCIA), lo cual da lugar a la metonimia PROVOCAR QUE UNA 
PERSONA NO EXISTA POR MATAR ${ }^{9}$, en la que hay una clara relación de causa-efecto. Esta metonimia subyace a las locuciones borrar del mapa, llevarse por delante y quitar de en medio, que destacan las implicaciones derivadas de la acción de matar a una persona en relación con el hecho de hacerla desaparecer. La proximidad conceptual entre matar a alguien y su inmediata inexistencia ${ }^{10}$, así como la violencia que pueden implicar las acciones literales de llevarse por delante a alguien y quitarlo de en medio, refuerzan su carácter disfemístico. Estas acciones, además, pueden verse como un acto descortés ya que suponen avasallar al que recibe la acción.

Los siguientes ejemplos, con su correspondiente explicación, muestran el carácter disfemístico de las tres locuciones propuestas:

(7) La bestia repetiría la huida que siguió a la cruel circunstancia que borró del mapa al clérigo. El carácter disfemístico de la locución se suma a las connotaciones negativas de los elementos bestia y cruel.

(8) si algún dia su escopeta se llevaba por delante a un compañero, repitió, se pegaría un tiro para no tener que acarrear esa carga el resto de sus dias. El valor disfemístico de la locución se refuerza mediante la referencia al arma que se utiliza para matar (una escopeta) y el uso del fraseologismo -también disfemístico-pegar un tiro.

(9) escuchamos en el apartamento de unos delincuentes: "A ese loco le quitaron de en medio, y él nunca supo quién le dio». El uso despectivo del sustantivo loco para referirse al difunto sumado a las connotaciones negativas del nombre delincuentes contribuye al valor disfemístico de la locución.

Por último, en relación con el evento de 'matar' también, cabe añadir dos procesos metonímicos más. El primero se centra en uno de los posibles efectos de matar a alguien, concretamente en la sangre que derrama el cuerpo de una persona muerta, para referirse a la acción de matar en sí misma, a partir de la metonimia UNA CONSECUENCIA DE MATAR POR LA ACCIÓN DE MATAR, presente en las locuciones correr sangre, correr rios de sangre y costar sangre. El segundo, por el contrario, toma como punto de referencia la acción de disparar a una persona para activar el posible efecto que produce sobre ella: causarle la muerte o matarla, a partir de la metonimia DISPARAR POR MATAR, en las locuciones dar/meter/pegar cuatro tiros, darlmeterlpegar dos tiros y darlmeterlpegar un tiro. Las dos metonimias y, por lo tanto, las locuciones que producen toman un detalle concreto de la acción de matar y concentran toda la atención en él, lo que contribuye a aumentar las connotaciones negativas del evento.

9 En el DiLEA no se han encontrado locuciones que ejemplifiquen la metonimia No ExIsTIR POR MORIR.

${ }^{10} \mathrm{La}$ inexistencia debe entenderse como lo opuesto a la 'vida del hombre' a partir de la segunda acepción de la voz existencia en el DLE. 
De manera análoga a la tabla 1, en la tabla 2 se muestran las metáforas y las metonimias que se han tratado, acompañadas de las locuciones disfemísticas en las que se materializan.

\begin{tabular}{|c|c|c|}
\hline \multicolumn{3}{|c|}{$\begin{array}{l}\text { TABLA 2. METÁFORAS Y METONIMIAS CONCEPTUALES DEL ÁMBITO } \\
\text { DE LA MUERTE EJEMPLIFICADAS CON LOCUCIONES DISFEMIISTICAS }\end{array}$} \\
\hline $\begin{array}{l}\text { METÁFORAS } \\
\text { CONCEPTUALES }\end{array}$ & Metonimias CONCEPTUALES & LOCUCIONES DISFEMÍSTICAS \\
\hline \multirow[b]{2}{*}{$\begin{array}{l}\text { La muerte es la falta de } \\
\text { integridad corporal }\end{array}$} & Perder la integridad por morir & perder el pellejo \\
\hline & Destruir la integridad por matar & $\begin{array}{l}\text { arrancarlpartirlromper el alma, arran- } \\
\text { carlsacar la piel a tiras, comer/sacar los } \\
\text { higados, hacer carnelmortadelalpicadillo, } \\
\text { retorcer el pescuezo, reventar como un } \\
\text { triquitraque }\end{array}$ \\
\hline \multirow{2}{*}{$\begin{array}{l}\text { La muerte es estar en el } \\
\text { lugar de la muerte }\end{array}$} & Ir al lugar donde se muere por morir & ir al degolladerolmatadero \\
\hline & $\begin{array}{l}\text { Llevar a una persona al lugar donde } \\
\text { se mata por matar }\end{array}$ & $\begin{array}{l}\text { llevar al degolladero, llevar/mandar al } \\
\text { matadero }\end{array}$ \\
\hline \multicolumn{2}{|c|}{ Metonimia CONCEPTUAL } & LOCUCIONES DISFEMÍSTICAS \\
\hline \multicolumn{2}{|c|}{ Provocar que una persona no exista por matar } & $\begin{array}{l}\text { borrar del mapa, llevarse por delante, quitar } \\
\text { de en medio }\end{array}$ \\
\hline \multicolumn{2}{|c|}{ Una consecuencia de matar por la acción de matar } & $\begin{array}{l}\text { correr sangre, correr ríos de sangre, costar } \\
\text { sangre }\end{array}$ \\
\hline \multicolumn{2}{|l|}{ Disparar por matar } & $\begin{array}{l}\text { darlmeter/pegar cuatro tiros, darlmeterlpe- } \\
\text { gar dos tiros, darlmeterlpegar un tiro }\end{array}$ \\
\hline
\end{tabular}

\section{CONCLUSIONES}

De lo expuesto en este trabajo se desprenden una serie de conclusiones sobre las locuciones eufemísticas y disfemísticas del campo de la muerte, y los mecanismos cognitivos implicados en su formación. Yendo de lo general a lo particular, la primera de estas conclusiones se relaciona con la identificación y la caracterización de las locuciones eufemísticas y disfemísticas. Aunque, a menudo, el eufemismo y el disfemismo son considerados fenómenos discursivos sujetos al contexto (Casas Gómez 2009, 2019; Crespo Fernández 2005; Fernández de Molina Ortés 2014), consideramos que, al menos, en el caso de las locuciones, es conveniente prestar atención también a otros aspectos que permitan ofrecer un tratamiento sistemático de estas unidades, más allá de identificar usos eufemísticos o disfemísticos particulares. Así, en este artículo, partimos de una serie de consideraciones que atienden a cuatro dimensiones de las locuciones y las relacionan con su naturaleza eufemística/disfemística: a) dimensión léxico-semántica, a partir de la imagen mental que evoca la combinación de palabras que forman la locución; b) dimensión pragmática, en relación con la imagen pública del hablante y su interlocutor; c) dimensión cognitivo-conceptual, atendiendo a las metáforas y las metonimias implicadas; 
y d) dimensión discursiva, referida a las funciones de mitigación, encubrimiento o realce expresivo de los eufemismos, y las funciones de motivación o refuerzo evocativo de los disfemismos.

En relación con la esfera interdicta que constituye el objeto de estudio de este trabajo, la segunda conclusión nos lleva a considerar que el estudio de los eufemismos y los disfemismos del ámbito de la muerte no debe restringirse exclusivamente al proceso de morir, sino que debe ampliarse e incluir la acción de matar también. A partir de las locuciones con referencias a la 'muerte' registradas en el DiLEA, se ha comprobado que la producción de eufemismos/disfemismos relacionados con 'matar' se muestra ciertamente productiva, de manera que su tratamiento no debe quedar desatendido en las investigaciones lingüísticas sobre el tabú de la muerte. Concretamente, de las 131 locuciones que el DiLEA registra en relación con el ámbito de la muerte, hay un total de 55 que se vinculan con la acción de matar, aunque en este trabajo no se tratan todas. Se ha observado, además, que hay locuciones que, en cierto modo, representan las dos caras del evento: la acción de matar y el proceso de morir, a partir de metáforas y metonimias con un fundamento común, pero con unas proyecciones metafóricas y metonímicas que se disponen de forma distinta. Por ejemplo, las locuciones llevar al degolladero ('matar') e ir al degolladero ('morir') -analizables como opuestos direccionales de consecuencia a partir de Penadés Martínez (2012: 243-244) - se basan en las metonimias LLEVAR AL LUGAR DONDE SE MATA POR MATAR E IR AL LUGAR DONDE SE MUERE POR MORIR, respectivamente, las cuales presentan un fundamento metonímico común, a pesar de que cada una se articula de un modo particular según el evento concreto que representa.

La tercera conclusión que se desprende de este artículo apunta a la sistematicidad en la formación de locuciones eufemísticas y disfemísticas de la muerte a partir de los recursos de la metáfora y la metonimia. Se ha comprobado que las locuciones analizadas se forman sobre una base metonímica que toma una parte del evento de 'morir' o de 'matar' para referirse a todo el evento completo. Esto demuestra, primero, la relevancia del recurso de la metonimia en la designación eufemística/disfemística de la muerte y, segundo, la posibilidad de que ciertos procesos que en estudios anteriores se han formulado como metáforas (ej: MORIR ES ESTAR CON DIOs), en realidad, se corresponden con metonimias (ej.: ESTAR CON DIOS POR MORIR) ya que implican solo un dominio cognitivo.

A partir de esta idea, como cuarta y última conclusión, en las locuciones eufemísticas, las metonimias tienden a apoyarse sobre una concepción metafórica de la muerte basada en creencias religiosas, mediante la cual se enfatizan los aspectos positivos de 'morir' por considerarse el paso previo al reencuentro con Dios y al descanso eterno en el Paraíso. Por su parte, las locuciones disfemísticas ponen de relieve la parte más violenta de la muerte, lo cual se ve reflejado en el proceso de morir (ej.: perder el pellejo, romperse el alma), pero sobre todo en la acción de matar (ej.: arrancar el pellejo, pegar cuatro tiros). La producción de disfemismos para referirse a 'matar' resulta lógica si se tiene en cuenta la violencia que, generalmente, se muestra inherente a esta acción, en contraste con el proceso de morir, que puede producirse de manera natural, sin implicar necesariamente un comportamiento agresivo. 
Para terminar, con este estudio se pretende invitar a la reflexión sobre la posibilidad de ampliar los aspectos tratados en la investigación lingüística sobre el tabú de la muerte, con el objetivo de: a) incluir el estudio de la acción de matar, de manera que el ámbito de la muerte no se identifique exclusivamente con el proceso de morir; b) prestar atención a la creación de disfemismos en este ámbito, además de la producción de eufemismos; c) tomar conciencia de la productividad asociada al recurso de la metonimia, con el fin de complementar la atención prestada a la metáfora; y d) considerar aspectos de tipo léxico-semántico, cognitivo-conceptual y pragmático que se sumen a la función discursiva del eufemismo/disfemismo en la identificación de locuciones eufemísticas/disfemísticas. 


\section{BIBLIOGRAFÍA}

Alonso Moya, Margarita (1978): «El empleo de la metáfora en la sustitución de términos tabú», Filología Moderna 63-64, 197-212.

BArley, Nigel (2000): Bailando sobre la tumba, Barcelona: Crónicas Anagrama.

Casas Gómez, Miguel (1986): La interdicción lingüistica. Mecanismos del eufemismo y disfemismo, Cádiz: Universidad de Cádiz.

Casas Gómez, Miguel (2009): «Towards a new approach to the linguistic definition of euphemism», Language Sciences 31, 725-739.

Casas Gómez, Miguel (2012a): «The expressive creativity of euphemism and dysphemism”, Lexis 7, 43-64.

Casas Gómez, Miguel (2012b): «El realce expresivo como función eufemística: a propósito de la corrección política de ciertos usos lingüísticos», en Ursula Reutner y Elmar Schafroth (eds.), Political Correctness. Aspectos politicos, sociales, literarios y mediáticos de la censura politica, Frankfurt am Main, Berlin, Bern, Bruxelles, New York, Oxford, Wien: Peter Lang, Studia Romanica et Linguistica, 61-79.

Casas Gómez, Miguel (2019): «Interdicción lingüística y metaforización eufemística/disfemística», en Antonio Briz et al. (coords.), Estudios lingüisticos en homenaje a Emilio Ridruejo. Vol. I, Valencia: Universitat de València, 255-267.

Cestero Mancera, Ana M. ${ }^{a}$ (2015): «La expresión del tabú: estudio sociolingüístico», Boletín de Filologia L-1, 71-105.

Chamizo Rodríguez, Pedro J. (2004): «La función social y cognitiva del eufemismo y el disfemismo",Pa-nace@V, 15, 45-51.

Crespo Fernández, Eliecer (2005): El eufemismo, el disfemismo y los procesos mixtos: la manipulación del referente en el lenguaje literario inglés, tesis doctoral, Alicante: Universidad de Alicante.

Crespo Fernández, Eliecer (2006): «The language of death. Euphemism and conceptual metaphorization in Victorian obituaries», SKY Journal of Linguistics 19, 101-130.

Crespo Fernández, Eliecer (2008): «La conceptualización metafórica del eufemismo en epitafios», Estudios Filológicos 43, 83-100.

Dobrovol'skij, Dimitrij y Elizabeth Pirrainen (2005): Figurative Language: Cross-cultural and Cross-linguistic Perspectives, Oxford: Elsevier.

Edeso Natalías, Verónica (2009): «Revisión del concepto de eufemismo: una propuesta de clasificación», Revista Internacional de Lingüistica Iberoamericana VII. 2-14, 147-163.

Fernández de Molina Ortés, Elena (2014): «La presencia de eufemismos y disfemismos en el campo semántico del cuerpo humano. Estudio sociolingüístico», Pragmalingüistica 22, 8-30.

Georgijev, Ivana (2019): «La muerte como un fenómeno metafísico en las paremias serbias y espańolas: enfoque etnolingüístico», en Andelka Pejovic et al. (eds.), Estudios hispánicos serbios y retos de la contemporaneidad. Actas de la segunda conferencia nacional de hispanistas serbios, Belgrado: Universidad de Belgrado, 143-154.

Lakoff, George (1987): Women, Fire and Dangerous Things: what Categories Reveal about the Mind, Chicago: University of Chicago Press. 
Lakoff, George y Mark Johnson (1980): Metaphors we Live by, Chicago: The University of Chicago Press.

Lakoff, George y Mark Turner (1989): More than Cool Reason: a Field Guide to Poetic Metaphor, Chicago / London: The University of Chicago Press.

Lope Blanc, Juan (1961): «Eufemismos mexicanos para "matar con arma de fuego"», Boletín de Filología 13, 283-294.

Mellado Blanco, Carmen (2013): «El campo conceptual TOD/MUERTE en alemán y español: eufemismos y disfemismos», Revista de Filología Alemana 21, 105-125.

Montero Cartelle, Enrique (1973): Aspectos léxicos y literarios del latín erótico, Santiago de Compostela: Universidad de Santiago de Compostela.

Montero Cartelle, Enrique (1981): «El eufemismo en Galicia (su comparación con otras lenguas romances)", Verba Anexo 7, Santiago de Compostela: Universidad de Santiago de Compostela.

Penadés Martínez, Inmaculada (2012): Gramática y semántica de las locuciones, Alcalá de Henares: Servicio de Publicaciones de la Universidad de Alcalá.

Penadés Martínez, Inmaculada (2019a): Diccionario de locuciones idiomáticas del español actual (DiLEA). URL: <http://www.diccionariodilea.es/>; 15/02/2020.

Penadés Martínez, Inmaculada (2019b): «La marcación lexicográfica de las locuciones eufemísticas», en R. González Ruiz, I. Olza y Ó. Loureda Lamas (eds.), Lengua, cultura, discurso. Estudios ofrecidos al profesor Manuel Casado Velarde, Pamplona: Ediciones Universidad de Navarra, 703-718.

Penadés Martínez, Inmaculada (en prensa): «La marcación diafásica de locuciones verbales eufemísticas», ELUA.

Real Academia Española: Corpus de Referencia del Español Actual (CREA). URL: <http://corpus. rae.es/creanet.html>; 11/03/2020.

Real Academia Española: Diccionario de la lengua española (DLE). URL: <https://dle.rae.es/>; $11 / 03 / 2020$.

Seco, Manuel, Olimpia Andrés y Gabino Ramos (2017, 2. ${ }^{a}$ ed.): Diccionario fraseológico documentado del español actual (DFDEA), Madrid, JdeJ Editores.

Zhou, Jiangrong (2018): Estudio cognitivo de la metáfora y metonimia del eufemismo lingüistico de "morir» en chino y análisis contrastivo y su aplicación en ELE, tesis doctoral, Madrid: Universidad Complutense de Madrid. 